\title{
Using a Spherical Crystallite Model With Vacancies to Relate Local Atomic Structure to Irradiation Defects in $\mathrm{ZrC}$ and $\mathrm{ZrN}$
}

\author{
Daniel T. Olive ${ }^{\mathrm{a}, 1}$, Hasitha Ganegoda ${ }^{\mathrm{a}}$, Todd Allen ${ }^{\mathrm{b}}$, Yong Yang ${ }^{\mathrm{c}}$, Clayton \\ Dickerson $^{\mathrm{d}, 2}$, Jeff Terry ${ }^{\mathrm{a}, *}$ \\ ${ }^{a}$ Department of Physics, Illinois Institute of Technology, Chicago, IL 60616, USA \\ ${ }^{b}$ Department of Engineering Physics, University of Wisconsin-Madison, WI 53706, USA \\ ${ }^{c}$ Nuclear Engineering Program, University of Florida, Gainsville, FL 32611, USA \\ ${ }^{d}$ Material Science Program, University of Wisconsin-Madison, WI 53706, USA
}

\begin{abstract}
Zirconium carbide and zirconium nitride are candidate materials for new fuel applications due to several favorable physicochemical properties. $\mathrm{ZrC}$ and $\mathrm{ZrN}$ have been irradiated at the Advanced Test Reactor National Scientific User Facility with neutrons at $800 \mathrm{C}$ to a dose of $1 \mathrm{dpa}$. Structural examinations have been made of the $\mathrm{ZrC}$ samples using high resolution transmission electron microscopy, and the findings compared with a previous study of $\mathrm{ZrC}$ irradiated with protons at $800 \mathrm{C}$. The use of X-ray absorption fine structure spectroscopy (XAFS) to characterize the radiation damage is also explored including a model based on spherical crystallites that can be used to relate EXAFS measurements to microscopy observations. A loss of coordination at more distant coordination shells was observed for both $\mathrm{ZrC}$ and $\mathrm{ZrN}$, and a model using small spherical crystallites suggested this technique can be used to study dislocation densities in future studies of irradiated materials.
\end{abstract}

\footnotetext{
* Corresponding author

Email address: terryj@iit.edu (Jeff Terry)

${ }^{1}$ Present affiliation: Department of Chemistry, University of California at Berkeley, Berkeley, CA 94720, USA, and Nuclear Science Division, Lawrence Berkeley National Laboratory, Berkeley, CA 94720, USA

${ }^{2}$ Present affiliation: Physics Division, Argonne National Laboratory, Argonne, IL, 60439, USA
}

Preprint submitted to Journal of Nuclear Materials

March 21, 2016

(C) 2016. This manuscript version is made available under the Elsevier user license http://www.elsevier.com/open-access/userlicense/1.0/ 


\section{Introduction}

Zirconium carbide was one of six ceramics that met melting temperature, neutronic, and irradiation performance requirements for composite fuels in gascooled fast reactors (GFR) [1]. Those properties and the ability to retain fission products also make $\mathrm{ZrC}$ a possible replacement for $\mathrm{SiC}$ in tri-isotropic (TRISO)coated fuel particles in high temperature applications $[2,3] . \mathrm{ZrN}$ has been proposed as a suitable material for fast neutron systems from the beginning of the development of nuclear fuel options [4]. Its high thermal conductivity, high melting point, and low neutron capture cross section make it an attractive choice for fast reactors and accelerator-driven transmutation systems [5].

The design for the Very High Temperature Reactor (VHTR) fuel for example must be able to withstand accident temperatures of $1600{ }^{\circ} \mathrm{C}$, fast neutron fluences of about $6 \times 10^{25} \mathrm{n} / \mathrm{m}^{2}$, and have good performance up to a burnup of $20 \%$ fissions per initial metal atom [6]. $\mathrm{ZrC}$ has a melting point of $3540{ }^{\circ} \mathrm{C}$, and its eutectic melting point with carbon of $2850^{\circ} \mathrm{C}$ should ensure temperature compatibility with new reactor applications [7]. Stoichiometric ZrN has a melting point of $2952^{\circ} \mathrm{C}$, while the non-stoichiometric phase has a reduced melting point down to $2952{ }^{\circ} \mathrm{C}[8]$. ZrN also has favorable chemical behavior with steel cladding, sodium, and nitric acid make it a candidate for homogeneous diluents for $\mathrm{PuN}$ and $\mathrm{PuO}_{2}$ fuel [9].

The response of $\mathrm{ZrC}$ and $\mathrm{ZrN}$ to irradiation has been studied, but often using $\mathrm{Au}$ or $\mathrm{Kr}$ ions, or protons [10]. Neutrons have been used, but often irradiation takes place within a few hundred degrees of room temperature, far away from pebble bed or helium gas cooled design requirements [10]. In this work we study high temperature, $800^{\circ} \mathrm{C}$, neutron irradiated $\mathrm{ZrC}$ and $\mathrm{ZrN}$ using electron microscopy and Extended X-ray Absorption Fine Structure (EXAFS) techniques. Using both a traditional EXAFS analysis as well as technique for determining the size of undamaged regions, we aim to demonstrate EXAFS can be used as a complementary technique to TEM which has been widely used for studying irradiated microstructures. 


\section{Methods}

Commercial grade $\mathrm{ZrC}$ rods (CERCOM Inc.) $3 \mathrm{~mm}$ wide, with a stoichiometric ratio of $\mathrm{C} / \mathrm{Zr}$ of 1.01 , were fashioned into TEM sample disks by slicing with a low speed diamond saw, followed by wet grinding to $250 \mu \mathrm{m}$, and polishing with $1 \mu \mathrm{m}$ diamond paste [11]. TEM examination showed no bubbles or voids, up to the image resolution of $1 \mathrm{~nm}$, and SEM images revealed a surface with low porosity with no visible inclusion phases, and an average grain size of about $24 \mu \mathrm{m}$ [11]. ZrN TEM sample disks were similarly prepared [12] using commercial grade $\mathrm{ZrN}$ rods (CERCOM Inc.) The $\mathrm{ZrN}$ was sub-stoichiometric, with ratio of $\mathrm{N} / \mathrm{Zr}$ of 0.80 , and also contained small amounts of carbon and oxygen impurities [12].

$\mathrm{ZrC}$ and $\mathrm{ZrN}$ TEM discs (3 mm wide, $0.25-0.3 \mathrm{~mm}$ thick) were subsequently neutron irradiated at the Advanced Test Reactor National Scientific User Facility (ATR-NSUF). The samples were held at $800^{\circ} \mathrm{C}$ as they were irradiated up to a dose of 1 displacement per atom (dpa). Temperature was controlled during irradiation by adjusting coolant gas flow in the envelope around the sample capsule. Based on the position of the samples in the reactor, the fast neutron flux (energy greater than $1 \mathrm{MeV}$ ) was $1 \times 10^{14} \mathrm{n} \mathrm{cm}^{-2} \mathrm{~s}^{-1}$ [13]. Dose to the samples, located in GFR-F1 capsule, was calculated by ATR-NSUF staff taking into account reactor configuration, power output, and operating history as described elsewhere[14, 15].

The EXAFS measurements were conducted at the Materials Research Collaborative Access Team (MRCAT) beamline at the Advanced Photon Source. EXAFS measurements at the MRCAT undulator beamline have been described in detail elsewhere $[16,17]$. An undulator produced polychromatic X-rays and wavelength was selected using a $\mathrm{Si}(111)$ double crystal monochromator. Higher harmonics were removed with the use of a Pt coated harmonic rejection mirror $[18,19]$. The energy was calibrated to the $\mathrm{Zr} \mathrm{K}$-edge $(17998 \mathrm{eV})$ of a $\mathrm{Zr}$ foil (The EXAFS Company) run in transmission geometry with incident and transmitted X-ray flux monitored by ionization chambers (Boyd Technologies). 
The $\mathrm{ZrC}$ and $\mathrm{ZrN}$ samples were measured in fluorescence geometry using a Lytle detector (The EXAFS Company). The $I_{0}$ ion chamber used a gas mix of $85 \% \mathrm{~N}_{2}: 15 \%$ Ar, the $\mathrm{I}_{\mathrm{t}}$ and fluorescence ion chamber used $100 \% \mathrm{Ar}$ as the fill gasses.

High Resolution TEM imaging was performed on the very same samples brought to the beamline using a Phillips CM200 TEM, and the rel-rod dark field images were taken using a JEOL 200CX TEM. TEM discs were mechanically dimpled to $10 \mu \mathrm{m}$ at the center and $100 \mu \mathrm{m}$ at the edge with sufficient mechanical integrity. The dimpling was performed using a Fischione dimpling grinder (model 200). The thickness of the discs was frequently monitored using an optical profilometer (Zygo NewView 7000) particularly after each step of changing to finer diamond grits. The perforation of TEM discs was completed by ion milling (Fischione 1010 ion mill), and the TEM specimens were finally cleaned using a $3 \mathrm{kV}$ ion beam at an angle of $9^{\circ} \mathrm{C}$ to eliminate an ion damage during previous high energy ion milling.

\section{Results and Discussion}

Figure 1(a) shows a high resolution TEM image of the irradiated microstructure of $\mathrm{ZrC}$, and the revealed streaks correspond to individual dislocation loops. The dislocation loops lie on the on habit plane of $\{111\}$ and display an angle of $70^{\circ}$ between the dislocation loops lying on habit planes of $(-1,1,-1)$ and $(1,1,-1)$, respectively, in the beam direction of [011]. A previous study was performed on the same material irradiated using a $2.6 \mathrm{MeV}$ proton beam at $800^{\circ} \mathrm{C}$ [11]. The Z contrast spherical aberration corrected STEM image of proton irradiated $\mathrm{ZrC}$ further confirms that those loops are interstitial type dislocation loops[20]. This indicates that the dislocation loops might be surrounded by $\mathrm{C}$ vacancies that have a much lower mobility as compared with $\mathrm{C}$ interstitials, however, there is no direct experimental evidence to confirm this yet. The relrods image and rel-rods streaks in the diffraction pattern of Fig. 1(b) further show that the dislocation loops contain stacking faults. 
a

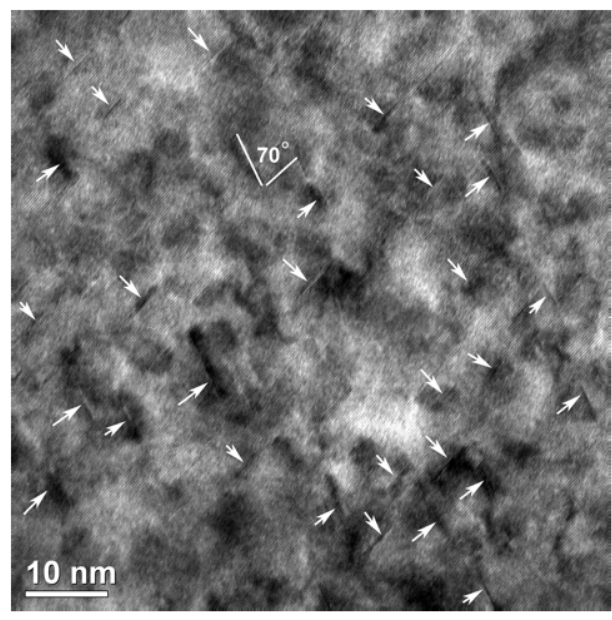

b

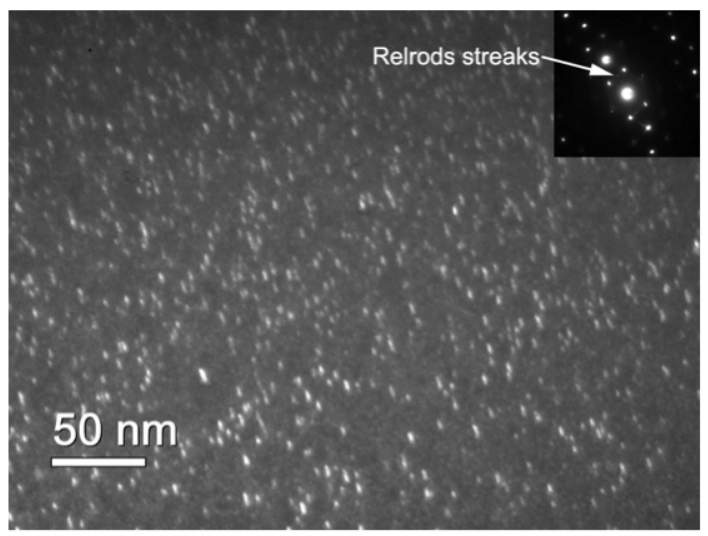

Figure 1: (a) High resolution TEM (HR-TEM) image of $\mathrm{ZrC}$, neutron irradiated at $800^{\circ} \mathrm{C}$ to 1dpa. Arrows indicate the location of edge-on dislocation loops in the habit planes of $(-1,1,-1)$ and $(1,1,-1)$. (b) Rel-rods dark field image of faulted dislocation loops in irradiated $\mathrm{ZrC}$.

The distance between dislocation loops is the distance between cores of two dislocation loops, calculated by considering each dislocation loop to be isolated in a cubic box. The average distance between dislocation loops is $13 \mathrm{~nm}$. The number density of the dislocation loops for $\mathrm{ZrC}$ is $4.26 \times 10^{23} \mathrm{~m}^{-3}$ and the average loop size (accounting for projection effects) is $6.5 \pm 0.2 \mathrm{~nm}$. These numbers are close to, but slightly higher that those found for the $\mathrm{ZrC}$ proton irradiated to $1.5 \mathrm{dpa}, 3.37 \times 10^{23} \mathrm{~m}^{-3}$ and $5.8 \pm 0.578 \mathrm{~nm}$, respectively [11]. The size of the undefected regions, taken as approximately equal to the average distance between loops minus the average dislocation diameter, is estimated as $6.5 \pm 0.2 \mathrm{~nm}$.

High magnification TEM results were also obtained for $\mathrm{ZrN}$, Figure 2, however, no rel-rod image could be obtained, which may have been due to interference from Moirè fringes. The number density of the dislocation loops is $5.2 \times 10^{22} \mathrm{~m}^{-3}$, and the average loop size (accounting for projection effects) is $7.1 \pm 0.6 \mathrm{~nm}$. These numbers are much higher than for $\mathrm{ZrN}$, proton irradiated to $0.75 \mathrm{dpa}$ at $800^{\circ} \mathrm{C}, 1.12 \times 10^{16} \mathrm{~m}^{-3}$ and $2.35 \mathrm{~nm}$, respectively[12]. The size 
between undefected regions is estimated to be $19.9 \pm 0.6 \mathrm{~nm}$ for $\mathrm{ZrN}$, suggesting under these irradiation conditions $\mathrm{ZrN}$ is less prone to accumulation of dislocation loops than $\mathrm{ZrC}$. The TEM observations for both samples were conducted at room temperature, the number of dislocations was observed to be constant even after a prolonged TEM session, suggesting escaping dislocations was not an issue.

The EXAFS data was analyzed according to the standard EXAFS analysis procedures [21, 18], data reduction including alignment, summation, calibration, and error correction was done with Athena [22]. Spectral fitting to determine structural parameters was performed using Artemis [22] with theoretical EXAFS paths created with FEFF6 [23, 24, 25, 26]. Error bars for each fitting parameter were determined by inversion of the covariance matrix [27].

The collected spectra suffered from self-absorption effects, altering the apparent amplitudes of the various scattering paths. Corrections were applied to the unirradiated samples using the method of Booth and Bridges [28] bringing their coordination numbers to the values expected from undamaged bulk samples. The same correction was then applied to the data from the irradiated samples, the resulting $k^{2}$ weighted EXAFS of the $\mathrm{ZrC}$ and $\mathrm{ZrN}$ samples in momentum space (k-space) and real-space (r-space) are shown in Fig. 3 and Fig. 4, respectively.

The FEFF model for the $\mathrm{ZrC}$ structure is based on the $\mathrm{NaCl}$ type, space group number 225 with lattice paramater $a=4.6828 \AA[29]$. Fitting of the EXAFS equation $[18,19]$,

$$
\chi(k)=\sum_{i} \frac{N_{i} S_{0}^{2} F_{i}(k)}{k R_{i}^{2}} \sin \left(2 k R_{i}+\phi_{i}(k)\right) e^{\left(-2 \sigma_{i}^{2} k^{2}\right)} e^{\frac{-2 R_{i}}{\lambda(k)}},
$$

to the measured $\chi(k)$ involved performing a non-linear least-squares fit summing over each scattering path used, $i$, in order to find the best values for the amplitude of each path, $N_{i}$, scattering half-path length, $R_{i}$, energy shift, $\Delta E_{0}$, and mean squared displacement, $\sigma_{i}^{2}$, also known as the EXAFS Debye-Waller factor. The values for the effective scattering amplitude, $F_{i}(k)$, effective scattering phase shift, $\phi_{i}(k)$, and mean free path, $\lambda(k)$, were taken from the FEFF 


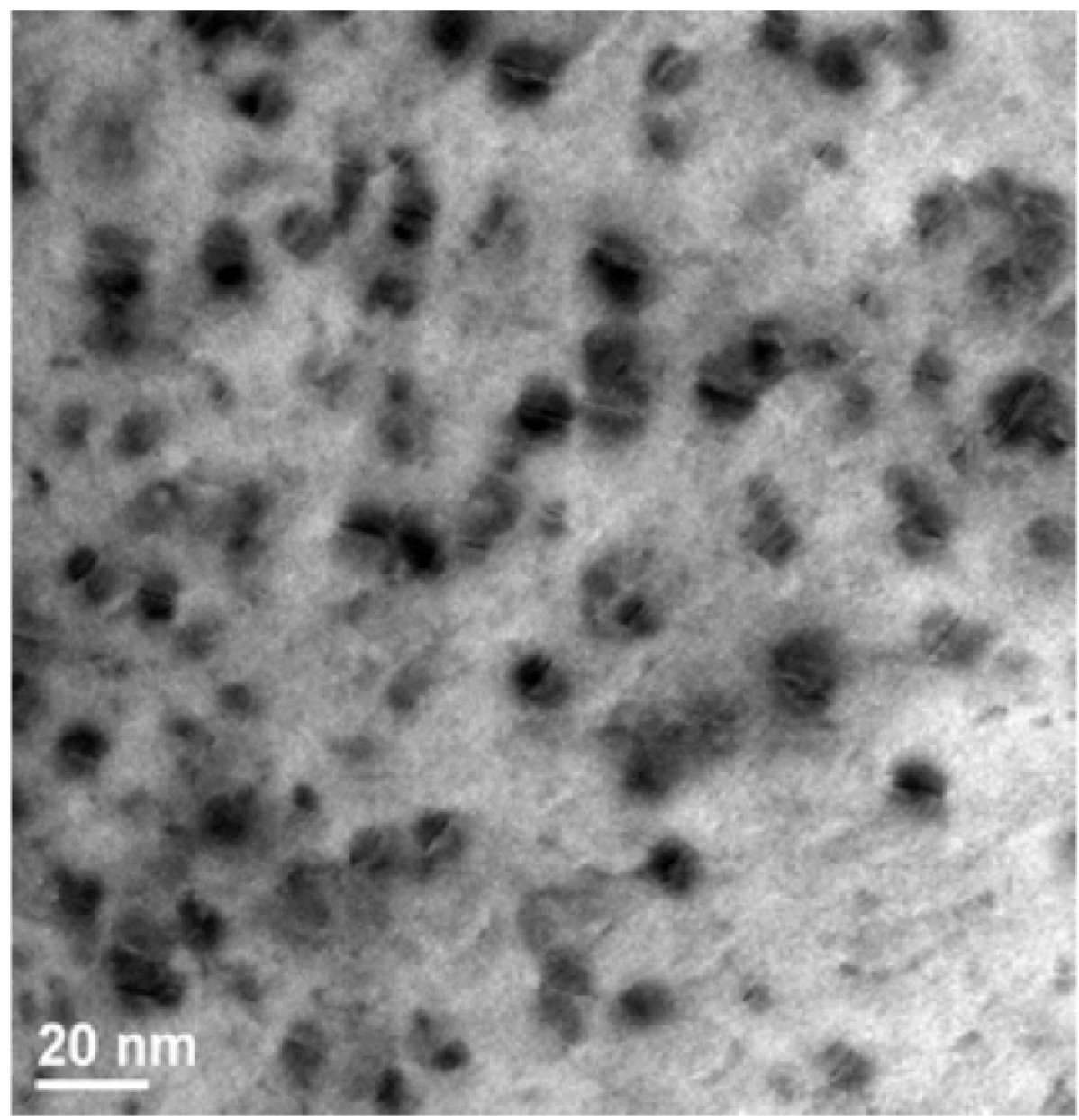

Figure 2: High magnification TEM image of $\mathrm{ZrN}$, neutron irradiated at $800^{\circ} \mathrm{C}$ to $1 \mathrm{dpa}$ : high density of dislocation loops are identified. 


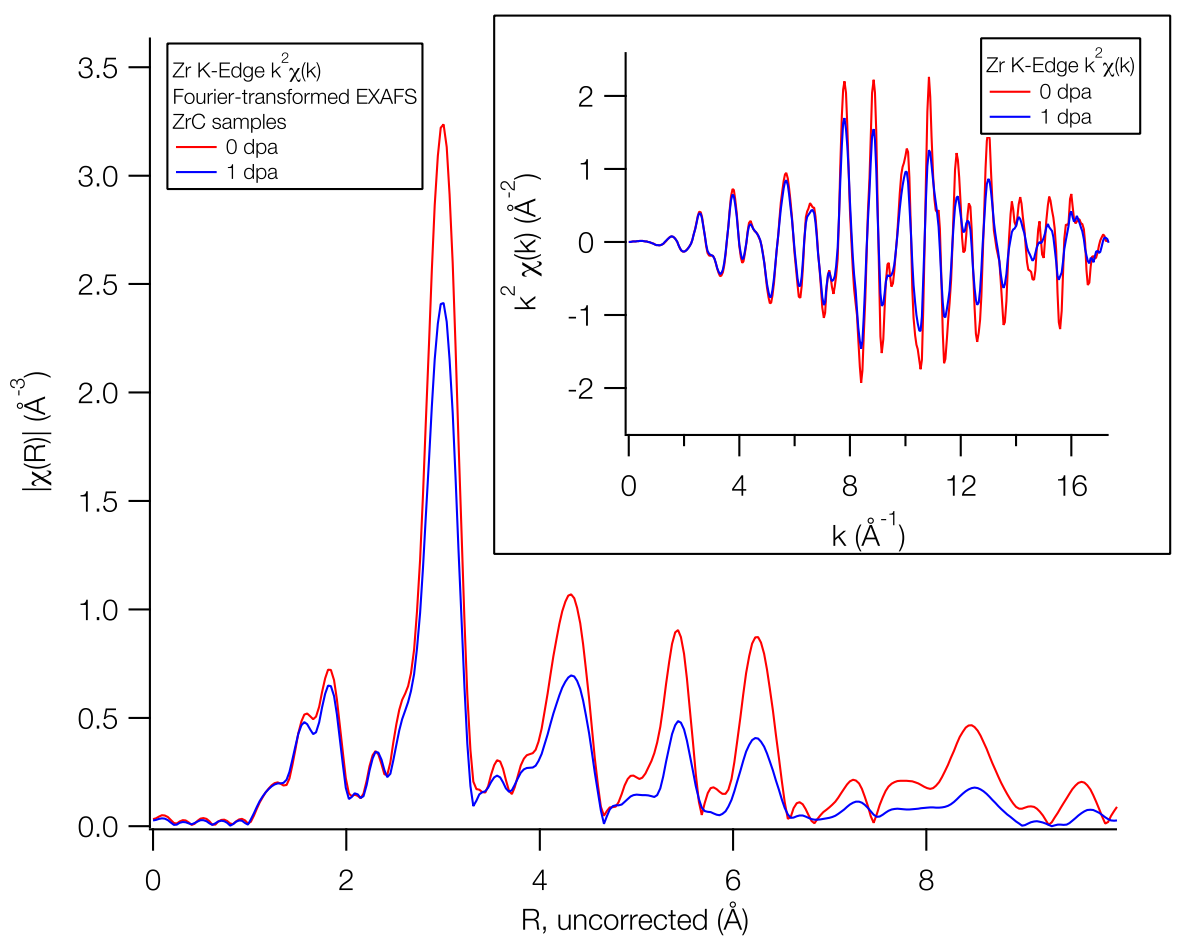

Figure 3: Zr K-edge X-ray absorption fine structure data for the 0 and 1 dpa $\mathrm{ZrC}$ samples, shown as the magnitude of the Fourier-transformed $k^{2}$ weighted data (inset), highlighting the loss of coordination with irradiation. 


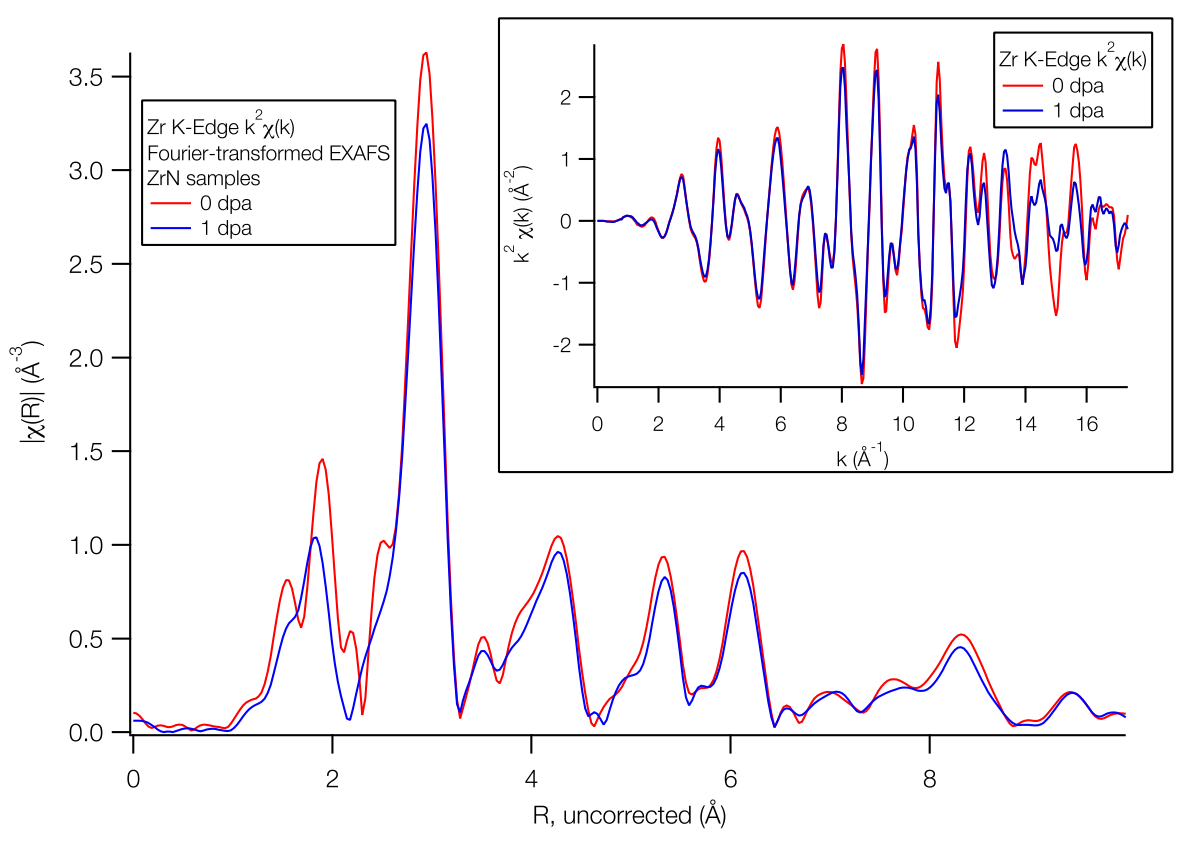

Figure 4: Zr K-edge X-ray absorption fine structure data for the 0 and $1 \mathrm{dpa} \mathrm{ZrN}$ samples, shown as the magnitude of the Fourier-transformed $k^{2}$ weighted data (inset), highlighting the loss of coordination with irradiation. 


\begin{tabular}{|c|c|c|c|c|c|c|}
\hline Path $^{\mathrm{a}}$ & $R_{\text {PerfectCrystal }}(\AA)$ & $R_{\text {Measured }}(\AA)$ & $\sigma^{2}\left(\AA^{2}\right)$ & $\mathrm{N}, 0$ dpa & $\mathrm{N}, 1$ dpa & $\begin{array}{c}\% \text { Amplitude } \\
\text { Difference }\end{array}$ \\
\hline $\mathrm{Zr}_{0} \rightarrow \mathrm{C}_{1} \rightarrow \mathrm{Zr}_{0}$ & 2.34 & $2.32 \pm 0.02$ & $0.008 \pm 0.002$ & $7.7 \pm 2.6$ & $6.6 \pm 1.7$ & $-14 \%$ \\
\hline $\mathrm{Zr}_{0} \rightarrow \mathrm{Zr}_{1} \rightarrow \mathrm{Zr}_{0}$ & 3.31 & $3.32 \pm 0.02$ & $0.004 \pm 0.001$ & $12.9 \pm 3.5$ & $9.3 \pm 0.5$ & $-28 \%$ \\
\hline $\mathrm{Zr}_{0} \rightarrow \mathrm{C}_{1} \rightarrow \mathrm{Zr}_{2} \rightarrow \mathrm{Zr}_{0}$ & 4.68 & $4.69 \pm 0.02$ & $0.005 \pm 0.001$ & $12.0 \pm 2.0$ & $7.8 \pm 1.2$ & $-35 \%$ \\
\hline $\mathrm{Zr}_{0} \rightarrow \mathrm{Zr}_{3} \rightarrow \mathrm{Zr}_{0}$ & 5.74 & $5.75 \pm 0.02$ & $0.003 \pm 0.001$ & $13.0 \pm 3.5$ & $6.0 \pm 1.7$ & $-53 \%$ \\
\hline $\mathrm{Zr}_{0} \rightarrow \mathrm{Zr}_{1} \rightarrow \mathrm{Zr}_{4} \rightarrow \mathrm{Zr}_{1} \rightarrow \mathrm{Zr}_{0}$ & 6.62 & $6.60 \pm 0.02$ & $0.005 \pm 0.001$ & $6.6 \pm 1.8$ & $2.8 \pm 0.8$ & $-57 \%$ \\
\hline
\end{tabular}

${ }^{\text {a }}$ The subscript represents $n^{\text {th }}$ coordination shell of a particular type of atom, 0 indicating the core scatting atom.

calculations.

Initially, both the $\mathrm{ZrC} 0$ dpa and 1 dpa data sets were modeled individually and only minor changes in path length and Debye-Waller factors between data sets were observed. Most of the changes were due to reduction in scattering path amplitude with increasing distance. However, the amplitudes and Debye-Waller factors are highly correlated, having correlation between $85 \%$ and $95 \%$ for all paths in both data sets. Although the fits were satisfactory, this resulted in some of the amplitude changes as a result of radiation damage being accounted for in the minimization by changes in disorder. However, TEM images of the irradiated sample provided visual evidence that with the exception of dislocation loops the overall crystal structure remained largely intact after irradiation. This is expected based on both simulations of neutron irradiated $\mathrm{ZrC}$ and TEM images from proton irradiated $\mathrm{ZrC}$ [11], as well as TEM images from fast neutron irradiated $\mathrm{ZrC}$ [10]. With that in mind the data were fit again simultaneously, sharing all parameters except for path amplitudes. The energy shifts and changes in scattering path length were also correlated between $40 \%$ and $85 \%$, but the differences between the independent fits was minimal and the results were consistent with the simultaneous fit. All other correlations were below $40 \%$, and no fitting restraints were applied to the models. The fitting results are summarized in table 1 and the data along with the total fit and fitting paths for the $1 \mathrm{dpa} \mathrm{ZrC}$ sample are shown in Fig. 5 as an example.

The $\mathrm{ZrN}$ structure used to create the FEFF model was also based on the structure in Wyckoff [29], but with the lattice parameter, $a=4.5835 \AA$ taken 


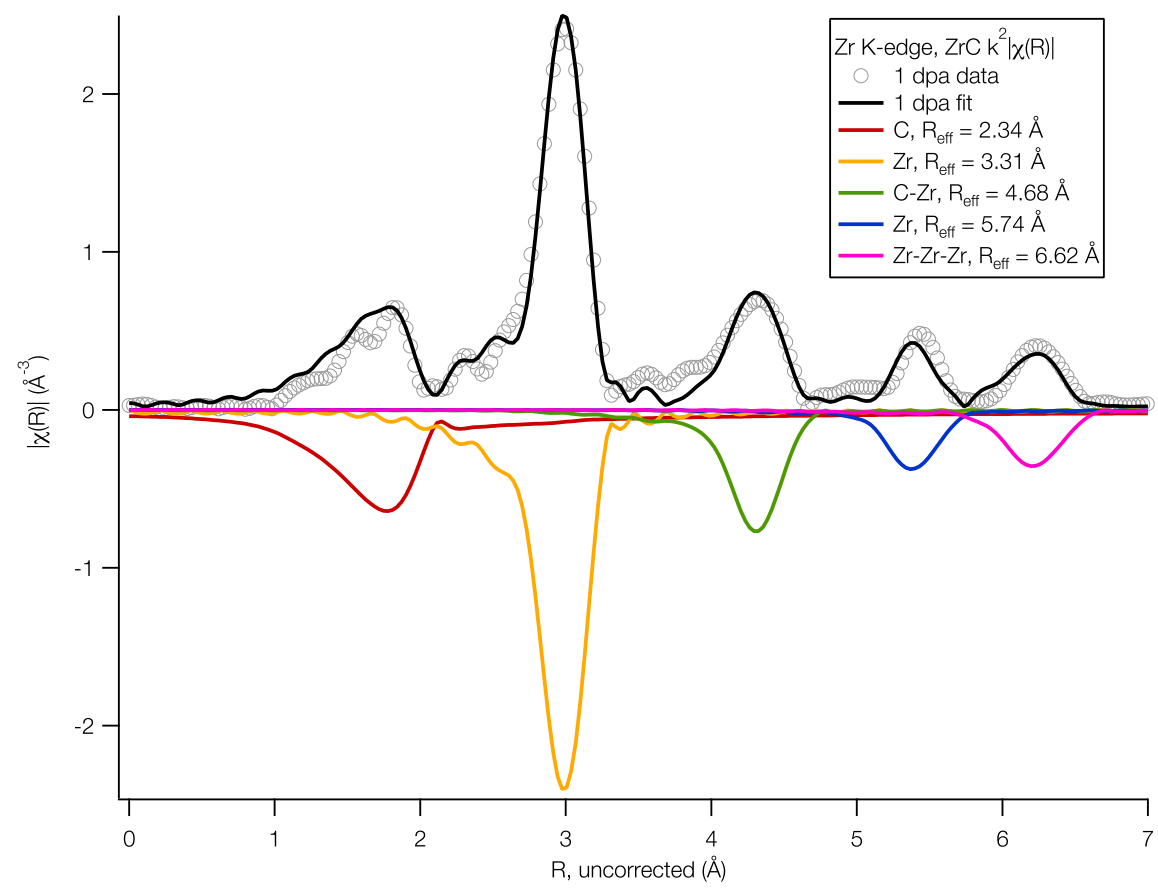

Figure 5: The magnitude of the Fourier-transformed $k^{2}$ weighted data and the fit for the 1 dpa $\mathrm{ZrC}$ sample are shown along with the fitting paths used in the model (reflected about the $x$-axis for clarity). 


\begin{tabular}{|c|c|c|c|c|c|c|}
\hline Path $^{\mathrm{a}}$ & $R_{\text {PerfectCrystal }}(\AA)$ & $R_{\text {Measured }}(\AA)$ & $\sigma^{2}\left(\AA^{2}\right)$ & $\mathrm{N}, 0$ dpa & $\mathrm{N}, 1$ dpa & $\begin{array}{c}\% \text { Amplitude } \\
\text { Difference }\end{array}$ \\
\hline $\mathrm{Zr}_{0} \rightarrow \mathrm{N}_{1} \rightarrow \mathrm{Zr}_{0}$ & 2.92 & $2.91 \pm 0.03$ & $0.012 \pm 0.01$ & $8.4 \pm 4.7$ & $5.3 \pm 3.1$ & $-36 \%$ \\
\hline $\mathrm{Zr}_{0} \rightarrow \mathrm{Zr}_{1} \rightarrow \mathrm{Zr}_{0}$ & 3.24 & $3.24 \pm 0.005$ & $0.003 \pm 0.002$ & $11.6 \pm 1.1$ & $10.2 \pm 0.8$ & $-12 \%$ \\
\hline $\mathrm{Zr}_{0} \rightarrow \mathrm{N}_{2} \rightarrow \mathrm{Zr}_{0} \rightarrow \mathrm{Zr}_{0}$ & 3.97 & $4.00 \pm 0.2$ & $0.012 \pm 0.01$ & $6.1 \pm 3.0$ & $8.6 \pm 1.2$ & $41 \%$ \\
\hline $\mathrm{Zr}_{0} \rightarrow \mathrm{Zr}_{2} \rightarrow \mathrm{Zr}_{0}$ & 4.59 & $4.67 \pm 0.01$ & $0.003 \pm 0.005$ & $9.3 \pm 4.0$ & $7.9 \pm 2.7$ & $-15 \%$ \\
\hline $\mathrm{Zr}_{0} \rightarrow \mathrm{Zr}_{3} \rightarrow \mathrm{Zr}_{0}$ & 5.62 & $5.62 \pm 0.01$ & $0.003 \pm 0.005$ & $12.8 \pm 3.0$ & $10.5 \pm 1.2$ & $-18 \%$ \\
\hline $\mathrm{Zr}_{0} \rightarrow \mathrm{Zr}_{1} \rightarrow \mathrm{Zr}_{1} \rightarrow \mathrm{Zr}_{0}$ & 6.48 & $6.46 \pm 0.02$ & $0.005 \pm 0.01$ & $6.7 \pm 1.8$ & $7.3 \pm 1.2$ & $9 \%$ \\
\hline $\mathrm{Zr}_{0} \rightarrow \mathrm{Zr}_{1} \rightarrow \mathrm{Zr}_{4} \rightarrow \mathrm{Zr}_{1} \rightarrow \mathrm{Zr}_{0}$ & 6.48 & $6.46 \pm 0.02$ & $0.006 \pm 0.005$ & $6.7 \pm 1.8$ & $2.8 \pm 1.2$ & $-58 \%$ \\
\hline
\end{tabular}

a The subscript represents $n^{\text {th }}$ coordination shell of a particular type of atom, 0 indicating the core scatting atom.

from Yang et al.[12]. Using the same technique as the $\mathrm{ZrC}$ fitting, the $\mathrm{ZrN} 0$ dpa and 1 dpa data sets were fit simultaneously, with all parameters shared except for path amplitudes. The fit was satisfactory except for features around $2 \AA$ (uncorrected) corresponding to the location of the first nitrogen shell, and around $3.8 \AA$ (uncorrected) which did not correspond to any expected multiple scattering peaks. These structures, possibly arising from the impurity phases were responsible for most of the statistical misfit. The shape of the first nitrogen scattering peak, and the low scattering contribution of the second nitrogen and outer zirconium double scattering peak made the fitting parameters difficult to determine for those paths if they were unconstrained. An Einstein model [27] applied to the Debye-Waller factors of all the paths was chosen in order to constrain the unruly fitting parameters without setting them to ad hoc values and instead tie them to some quantity that was still optimized in the fitting procedure. Removing those paths would have removed the difficulty, but the improvement in the fit was determined to be statistically significant [30]. The fitting results are summarized in table 2 , and the data along with the total fit and fitting paths for the 1 dpa ZrN sample are shown in Fig. 6 .

The decrease in coordination number evident in the EXAFS analysis is not coming from amorphization of the sample, but rather from the change in local environment that the scattering atom sees as a result of being surrounded by dislocation loops. By analogy if we consider a spherical nanoparticle the atoms near the center will have a coordination environment much like the bulk mate- 


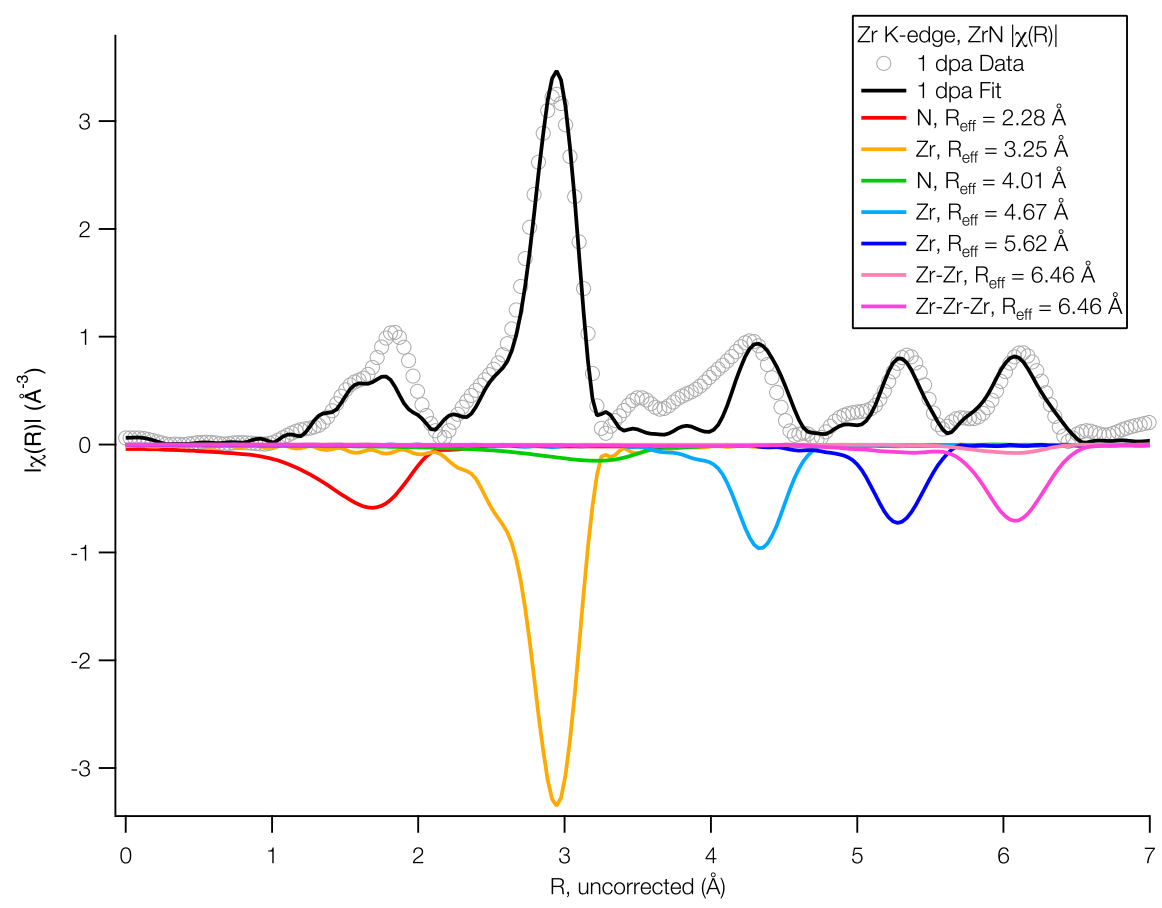

Figure 6: The magnitude of the Fourier-transformed $k^{2}$ weighted data and the fit for the 1 dpa $\mathrm{ZrN}$ sample are shown along with the fitting paths used in the model (reflected about the $x$-axis for clarity). 
rial, but those closer to the surface will suffer from a loss of neighbors. EXAFS however will sample all the atoms, and the effect only becomes noticeable as the particle size shrinks to the point where a significant fraction of the atoms are surface-like.

For example, using the distance to the first near neighbor in $\mathrm{ZrC}, 2.34 \AA$, for the diameter of the surface shell around a $5 \mathrm{~nm}$ particle, we find that about $13 \%$ of the atoms are on the surface, and so there should be a corresponding drop in first near neighbor amplitude. However, the EXAFS signal is sensitive to more than just the nearest neighbors, and so those atoms close to but not on the surface will show evidence of missing neighbors in extended coordination shells. The fraction of volume in the same $5 \mathrm{~nm}$ particle experiencing a termination effect at $5 \AA$ for example jumps to about $27 \%$.

Several models have been utilized to determine the average coordination numbers of nanoparticles in specific configurations, but often they utilize only the first near neighbor, and in any case they rely on knowing the particular morphology of the particle in question $[31,32,33,34]$. In order to estimate the mean size of the undefected regions of the sample we employ a more widely applicable approach, at the expense of some precision based upon the technique used by Borowski et. al $[35,36]$ and Calvin et. al. [37, 34]. If we consider a spherical crystallite of radius $R$, the reduction in average coordination, compared to the bulk material, at a given distance $r$ is given by $[34,38]$ :

$$
N_{\text {nano }}=\left[1-\frac{3}{4}\left(\frac{r}{R}\right)+\frac{1}{16}\left(\frac{r}{R}\right)^{3}\right] N_{\text {bulk }},
$$

where $N_{\text {bulk }}$ is the coordination number present in the bulk (undamaged) compound, and $N_{\text {nano }}$ is the lowered coordination number due to size effects.

To investigate the applicability of the model, spherical clusters of $\mathrm{ZrC}$ were created using the programs debyer [39, 40, 41] and gosam [42]. Radial distribution functions (RDFs) [43] were calculated for each of the clusters. The RDF, calculated [43] by a summation

$$
R(r)=\sum_{\nu} \sum_{\mu} \frac{b_{\nu} b_{\mu}}{\langle b\rangle^{2}} \delta\left(r-r_{\nu \mu}\right),
$$


over atomic positions $\nu$, and $\mu$, and where $b$ is a scattering factor and $r_{\nu \mu}$ is the magnitude of the separation of the atoms [43]. The RDFs for clusters of radius $5 \AA, 10 \AA, 15 \AA, 25 \AA, 50 \AA, 100 \AA$, and $200 \AA$, were fit to the bulk coordination values using equation 2. The results indicate the excellent ability of the spherical model to fit the crystallite size. The largest misfit was for the $5 \AA$ particle, $7.6 \%$, which dropped to $1.2 \%$ or less for all the larger sizes.

It is also possible that point defects may alter the particle size as fit by the model. To study this possibility, spherical models of $\mathrm{ZrC}$ were again created using debyer [39, 40, 41] and gosam [42], but with vacancies created at random positions with fixed percentages of $0 \%, 1 \%, 2 \%, 5 \%, 10 \%, 15 \%, 20 \%$, and $25 \%$. The vacancies were randomly generated multiple times to gain a representative distribution. As the percentage of vacancies increases, the spherical model produces erroneously smaller fits, $13.26 \pm 0.96 \AA$ for a $25 \AA$ radius particle with $25 \%$ random vacancies. By altering equation 2 to account for a fraction of atoms removed as vacancies,

$$
N_{\text {nano }}=\left[1-\frac{3}{4}\left(\frac{r}{R}\right)+\frac{1}{16}\left(\frac{r}{R}\right)^{3}\right]\left(N_{\text {bulk }}(1-v)\right),
$$

where the new term multiplied by $N_{\text {bulk }}$ accounts for the fraction of vacancies, $v$, in the crystal, it once more becomes possible to successfully model the computer generated clusters, as seen in Fig. 7.

The best fit values of cluster radii and vacancy populations were determined by fitting the self-absorption corrected Fourier transform from the irradiated sample to that of the unirradiated sample, using the vacancy corrected spherical model at each distance $r$. The diameter of the undefected regions of $\mathrm{ZrC}$ was found to be $1.8 \pm 0.08 \mathrm{~nm}$ at the $95 \%$ confidence interval, as shown in Fig. 8 . The vacancy percentage was equal to zero within the error bars. This is smaller than the undefected region size obtained via TEM, $6.5 \pm 0.2 \mathrm{~nm}$ The simplicity of the model, requiring only a single variable be fit, is also a potential limitation. The model will suffer inaccuracies if serious departures from spherical regions occur, additionally, if there is a broad distribution of crystallite sizes the result will be biased toward smaller sizes [34]. The $\mathrm{ZrN}$ fit with zero vacancies as 


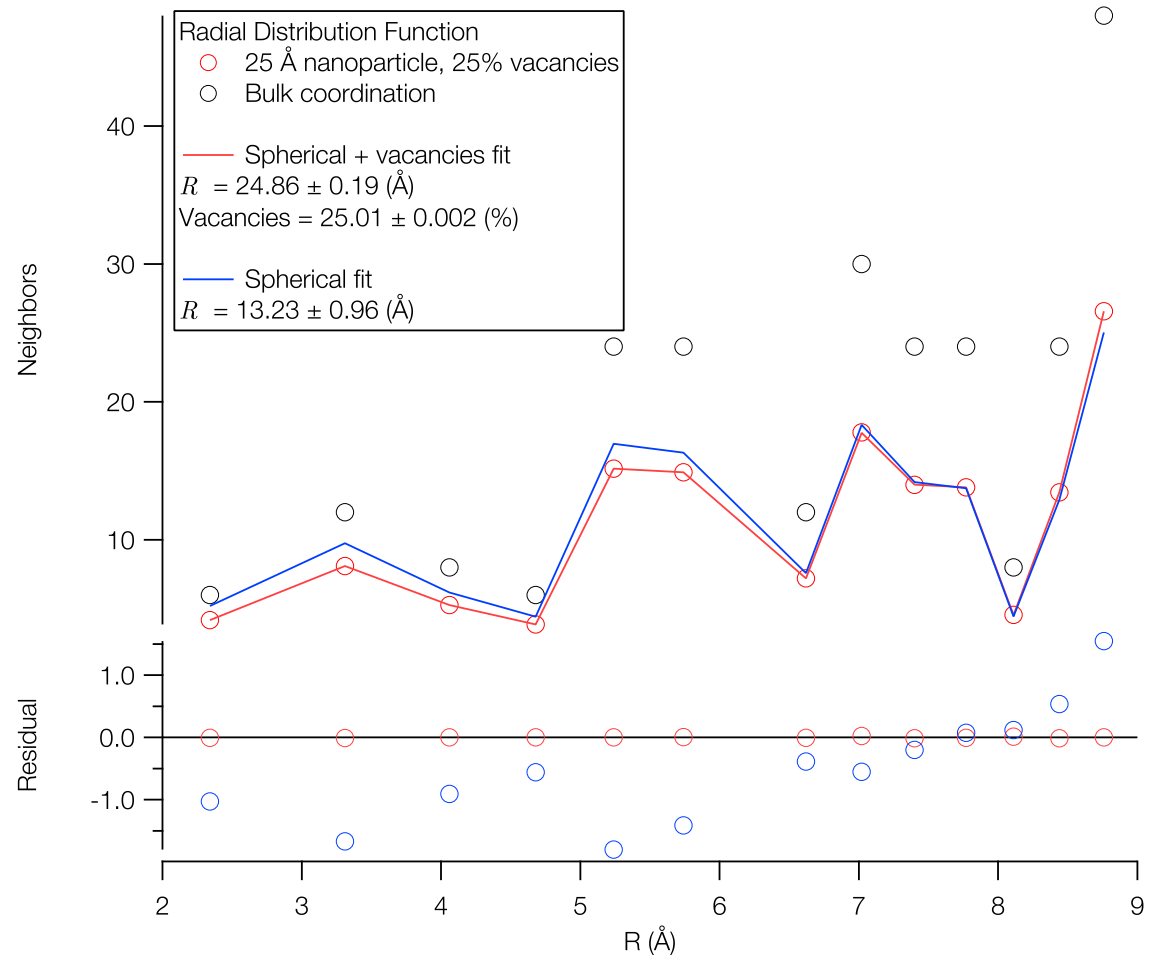

Figure 7: The radial distribution function calculated for a $25 \AA$ radius spherical particle with $25 \%$ randomly placed vacancies, fit with the spherical and vacancy corrected spherical models (top), and the residual differences between the fits and the RDFs (bottom). 
well, although to reign in the error bars required restricting the fitting range when using the vacancy corrected fit due to interference from the first carbon scattering peak. The diameter of the undefected region of $\mathrm{ZrN}$ was found to be $4.0 \pm 0.4 \mathrm{~nm}$ at the $95 \%$ confidence interval, as shown in Fig. 9. This is also smaller than the TEM determination of $19.9 \pm 0.6 \mathrm{~nm}$.

We note that both EXAFS and TEM measurements show larger undefected region sizes in $\mathrm{ZrN}$, with EXAFS predictions systematically 3.5 to 5 times smaller. It is well known that EXAFS measurements typically estimate a greater fraction of damaged material compared to TEM and X-ray diffraction (XRD) measurements $[44,45]$. In the case of discrete particles, this type of EXAFS size estimate has been known to estimate particle sizes almost an order of magnitude smaller than XRD[37], and several times smaller than TEM[44]. Extra disorder caused by relaxation effects at the boundaries, coupled with the inability of TEM to capture the smallest sized defects in a material, are thought to be responsible for the disparity between the TEM measurements and our EXAFS results[44, 45].

This data suggests that the presence of dislocation loops, primary along the $\{111\}$ family of planes, might, through overlapping displacement fields introduce enough disorder to effectively isolate small regions from each other at least with respect to EXAFS measurements. Defects, even point defects, in a radiation damaged material displace neighboring atoms resulting in a complicated and extensive displacement field. These distortions some of which are below the capability of TEM to resolve, are partly responsible for the loss of amplitude see in EXAFS spectra. We note the fact that the $\mathrm{Zr}$ data from these samples can be fit with such a simple model is not necessarily due to simplicity of the model, for it is not universally applicable to all cases of radiation damage. For example, in neutron irradiated mod.9Cr1Mo steel the damage around Mo was confined to the nearest neighbors[46], and equation 2 would not have been able to fit that data. Even with cause for skepticism about the absolute accuracy of the size determinations made, this technique should still produce a reliable relative metric for comparisons between different materials, as we have done 
here, or as a way of tracking the evolution of a structure as a function of dose.

Equation 4 assumes a random distribution of vacancies in the particle, however, vacancies in the material can potentially form clusters, as seen in other materials with high enough doses [47] or in simulations [48] of $\mathrm{ZrC}$, but not seen in TEM with proton irradiated $\mathrm{ZrC}$ [11] or in the present study at these low doses. However, since the limit of detection with our TEM study is approximately $1 \mathrm{~nm}$, further simulations were carried out to determine the effects of small vacancy clusters on the spherical particle model. The program DISCUS [49] was used to generate spherical particles and randomly place vacancy clusters throughout, the RDFs were determined using debyer [39, 40, 41], and fit using Larch [50] with scripts similar to those used in the single point vacancy tests to compile the results.

Spherical particles with a $50 \AA$ radius were created, and vacancy clusters were generated with five radii from $2.34 \AA$ to $5.24 \AA$ corresponding to the removal of the first through fifth near-neighbors. Fitting the particles with the model from equation 2 produces results with small error bars, less than $5 \%$ for all the variations tested, and best fit radii which underestimate the particle size. For example, with a vacancy fraction of only $0.8 \%$, and a cluster size of $2.34 \AA$ the particle radius fit to $46.7 \pm 0.2 \AA$, and with a vacancy fraction of $7 \%$, a cluster size of $5.24 \AA$ the particle radius fit to $33.9 \pm 0.3 \AA$. However, when vacancy clusters are present in large enough amounts, the model will fit with slightly higher values for coordination number for the first several shells, suggesting that if the EXAFS data represent a true measure of the coordination and if the fit is systematically high, that a high density of vacancy clusters could be present.

When fitting the particles with equation 4 the model would underestimate the fraction of vacancies present in the particle, an effect which worsened as the size and number of the vacancy clusters increased. At high vacancy fractions large error bars indicated a problem applying that model to this system, however, at low enough vacancy fractions clusters of vacancies could be reasonably fit, although with an underestimated cluster size. For example, with 
$7 \%$ vacancies caused by $5.24 \AA$ radius clusters the $50 \AA$ radius particle fit to $37.8 \pm 0.7 \AA$. When the vacancy fraction increased to $30 \%$, the particle radius fit to $21.7 \pm 1.4 \AA$, an uncertainty of about $6 \%$. Smaller vacancy clusters produced similar errors in fits, although at lower vacancy fractions. The smallest clusters, $2.34 \AA$ had a similar error, $46.3 \pm 2.3 \AA$, or about $5 \%$ with a vacancy fraction of only $8 \%$.

Since the fits in figures 8 and 9 do not show a systematic overestimation of amplitude, and do not indicate a high concentration of vacancies, the results from the simulation suggest there is not a large concentration of vacancies or vacancy clusters below the TEM limit of detection. Keilholtz et al. [51] studied fast neutron irradiated $\mathrm{ZrC}$ at $130-355{ }^{\circ} \mathrm{C}[10]$, below the annealing temperature, and found a volume increase (up to $3 \%$ ) primarily due to agglomerates of point defects or formation of gas bubbles, along with severe fracturing. Up to $1 \%$ volume increase was attributed to lattice expansion[51]. Further high temperature studies showed a reduction of volume expansion and elimination of sample fracture[10]. Our results are consistent with increased defect mobility at higher temperatures, leading to a reduced agglomeration of point defects. Gaining a better understanding of the effects a single defect in the structure has on the EXAFS of all the neighboring atoms may provide a way for this simple quantification to better describe the radiation damage in materials.

\section{Conclusions}

To summarize, we have demonstrated the use of EXAFS to model the size of defected regions in neutron irradiated $\mathrm{ZrC}$ and $\mathrm{ZrN}$. $\mathrm{ZrN}$ was more radiation tolerant than $\mathrm{ZrC}$ under these irradiation conditions. The changes in local atomic structure were related to, and consistent with, microscopy observations. This technique should be applicable to studying further changes with irradiation dose, and having another technique available should prove useful as dealing with higher levels of radioactivity from activated samples makes post-irradiation examination more difficult. Additionally, these results may be useful for bench- 


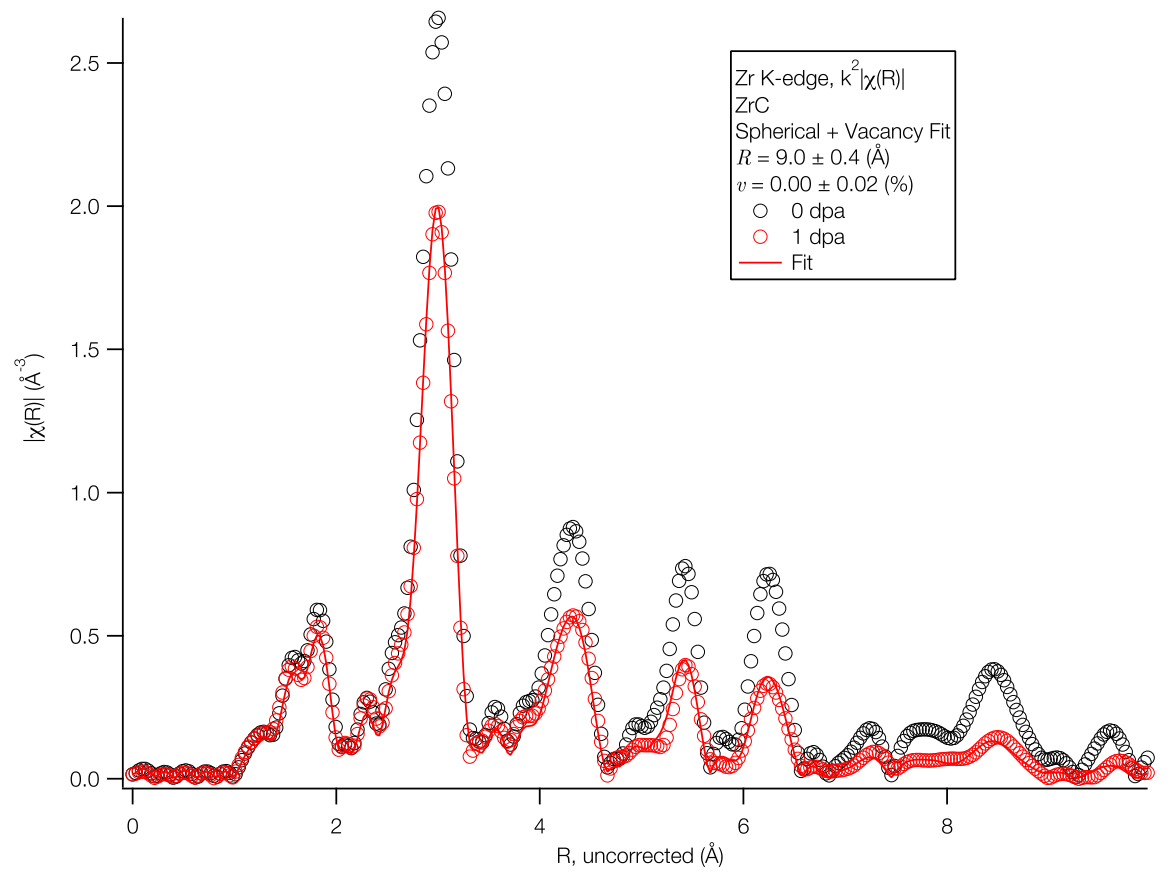

Figure 8: Fitting results of the unirradiated $\mathrm{ZrC}$ sample to the 1 dpa sample, using the vacancy corrected spherical crystallite model. 


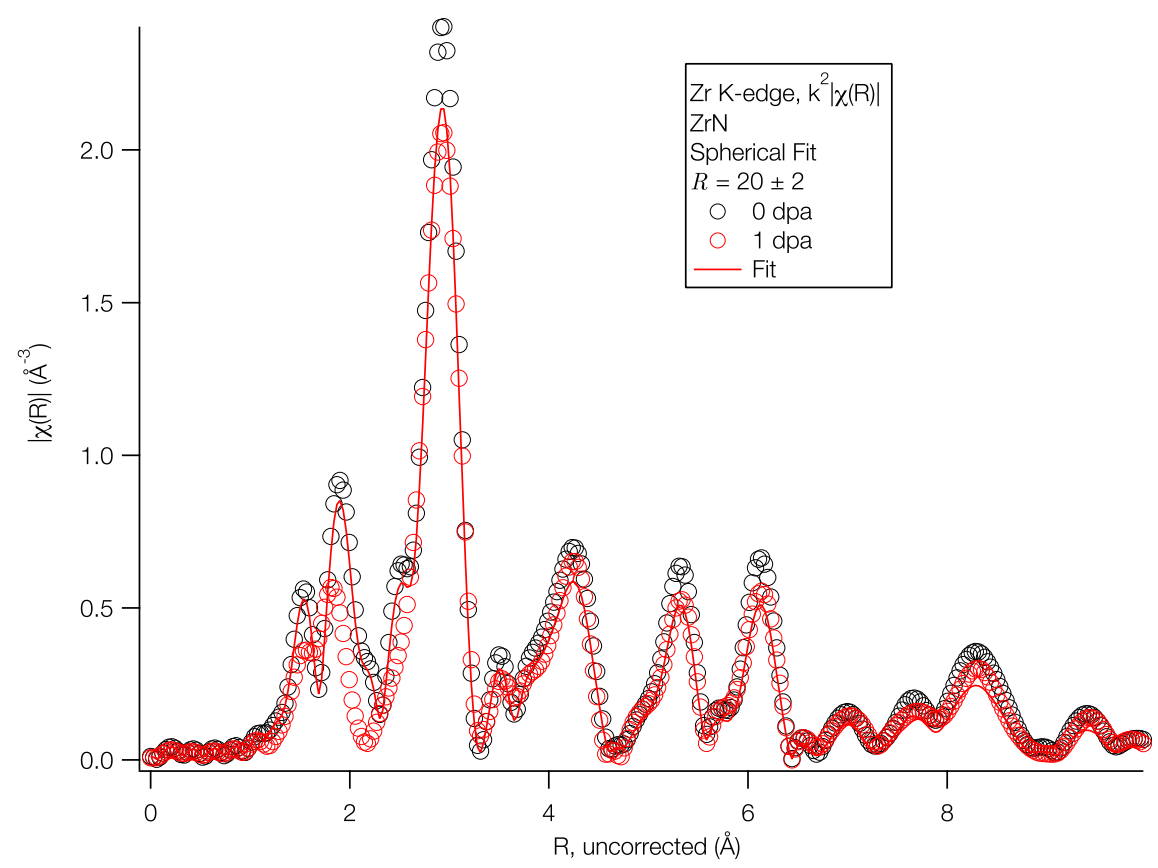

Figure 9: Fitting results of the unirradiated $\mathrm{ZrN}$ sample to the 1 dpa sample, using the spherical crystallite model. 
marking molecular dynamics and kinetic Monte Carlo studies of radiation damage by providing a point of comparison for RDFs generated by simulations. Further applications of this technique on other materials are ongoing.

\section{Acknowledgments}

The authors wish to thank UW Reactor director, Robert Agasie, for assistance with sample. This research constituted a part of the Ph.D. thesis of one of the authors, D. T. O. MRCAT operations are supported by the U.S. Department of Energy and the MRCAT member institutions. Use of the Advanced Photon Source was supported by the U.S. Department of Energy, Office of Science, Office of Basic Energy Sciences, under Contract No. DE-AC0206CH11357. ATR-NSUF is funded by the U.S. Department of Energy, Office of Nuclear Energy.

\section{References}

[1] K. D. Weaver, T. C. Toemeier, D. E. Clark, E. E. Feldman, E. A. Hoffman, R. B. Vilim, T. Y. C. Wei, J. Gan, M. K. Meyer, W. F. Gale, M. J. Driscol, M. Golay, G. Apostolakis, K. Czerwinski, Gen IV nuclear energy systems gas-cooled fast reactor (GFR) FY-04 annual report, Tech. Rep. INEEL/EXT-04-02361, Idaho National Engineering and Environmental Laboratory (2004).

[2] K. Sawa, S. Ueta, Research and development on HTGR fuel in the HTTR project, Nuclear Engineering and Design 233 (1) (2004) 163-172.

[3] K. Minato, T. Ogawa, K. Fukuda, H. Sekino, I. Kitagawa, N. Mita, Fission product release from $\mathrm{ZrC}$-coated fuel particles during post-irradiation heating at 1800 and $2000^{\circ} \mathrm{C}$, Journal of Nuclear Materials 249 (2) (1997) $142-149$.

[4] M. Streit, F. Ingold, Nitrides as a nuclear fuel option, Journal of the European Ceramic Society 25 (12) (2005) 2687-2692. 
[5] M. Burghartz, G. Ledergerber, H. Hein, R. R. Van der Laan, R. J. M. Konings, Some aspects of the use of $\mathrm{ZrN}$ as an inert matrix for actinide fuels, Journal of nuclear materials 288 (2) (2001) 233-236.

[6] S. Ueta, J. Aihara, K. Sawa, A. Yasuda, M. Honda, N. Furihata, Development of high temperature gas-cooled reactor (HTGR) fuel in japan, Progress in Nuclear Energy 53 (2011) 788-793.

[7] S. Ueta, J. Aihara, A. Yasuda, H. Ishibashi, T. Takayama, K. Sawa, Fabrication of uniform $\mathrm{ZrC}$ coating layer for the coated fuel particle of the very high temperature reactor, Journal of Nuclear Materials 376 (2) (2008) $146-151$.

[8] L. Gribaudo, D. Arias, J. Abriata, The n-zr (nitrogen-zirconium) system, Journal of phase equilibria 15 (4) (1994) 441-449.

[9] H. Kleykamp, Selection of materials as diluents for burning of plutonium fuels in nuclear reactors, Journal of Nuclear Materials 275 (1) (1999) 1-11.

[10] L. L. Snead, Y. Katoh, S. Kondo, Effects of fast neutron irradiation on zirconium carbide, Journal of Nuclear Materials 399 (2-3) (2010) 200-207.

[11] Y. Yang, C. A. Dickerson, H. Swoboda, B. Miller, T. R. Allen, Microstructure and mechanical properties of proton irradiated zirconium carbide, Journal of Nuclear Materials 378 (3) (2008) 341-348.

[12] Y. Yang, C. A. Dickerson, T. R. Allen, Radiation stability of ZrN under 2.6 MeV proton irradiation, Journal of Nuclear Materials 392 (2) (2009) 200-205.

[13] FY 2008 advanced test reactor national scientific user facility users' guide, Tech. Rep. INL/EXT-07-13577, Idaho National Laboratory (2007).

[14] D. J. Utterbeck, G. S. Chang, Advanced fuel cycle initiative afc-1d, afc$1 \mathrm{~g}$ and afc-1h irradiation report, Tech. Rep. INL/EXT-05-00704, Idaho National Laboratory (2005). 
[15] K. D. Weaver, T. C. Totemeier, D. E. Clark, E. E. Feldman, E. A. Hoffman, R. B. Vilim, T. Y. C. Wei, J. Gan, M. K. Meyer, W. F. Gale, M. J. Driscol, M. Golay, G. Apostolakis, K. Czerwinski, Gas-cooled fast reactor (gfr) fy04 annual report, Tech. Rep. INEEL/EXT-04-02361, Idaho National Laboratory (2004).

[16] Y. Liu, J. Terry, S. Jurisson, Pertechnetate immobilization with amorphous iron sulfide, Radiochimica Acta 96 (12) (2008) 823-833.

[17] J. Terry, B. Grzenia, D. Papagiannopoulou, J. Kyger, S. Jurisson, J. Robertson, Structural determination of ${ }^{99} \mathrm{Tc}$ radiopharmaceuticals and compounds using X-ray absorption spectroscopy, Journal of Radioanalytical and Nuclear Chemistry 263 (2) (2005) 531-537.

[18] D. C. Koningsberger, R. Prins (Eds.), X-ray Absorption: Principles, Applications, Techniques of EXAFS, SEXAFS and XANES, John Wiley and Sons Inc., New York, NY, 1988.

[19] G. Bunker, Introduction to XAFS: A Practical Guide to X-Ray Absorption Fine Structure Spectroscopy, Cambridge University Press Cambridge, UK, 2010.

[20] Y. Yang, W.-Y. Lo, C. Dickerson, T. R. Allen, Stoichiometry effect on the irradiation response in the microstructure of zirconium carbides, Journal of Nuclear Materials 454 (1) (2014) 130-135.

[21] J. J. Rehr, R. C. Albers, Theoretical approaches to x-ray absorption fine structure, Reviews of modern physics 72 (3) (2000) 621-654.

[22] B. Ravel, M. Newville, ATHENA, ARTEMIS, HEPHAESTUS: Data analysis for x-ray absorption spectroscopy using IFEFFIT, Journal of Synchrotron Radiation 12 (4) (2005) 537-541.

[23] J. Mustre de Leon, J. J. Rehr, S. I. Zabinsky, R. C. Albers, Ab initio curvedwave x-ray-absorption fine structure, Physical Review B 44 (9) (1991) 41464156. 
[24] J. J. Rehr, R. C. Albers, Scattering-matrix formulation of curved-wave multiple-scattering theory: Application to x-ray-absorption fine structure, Physical Review B 41 (12) (1990) 8139-8149.

[25] J. Rehr, J. Mustre de Leon, S. Zabinsky, R. Albers, Theoretical x-ray absorption fine structure standards, Journal of the American Chemical Society 113 (14) (1991) 5135-5140.

[26] J. J. Rehr, R. C. Albers, S. I. Zabinsky, High-order multiple-scattering calculations of x-ray-absorption fine structure, Physical Review Letters 69 (23) (1992) 3397-3400.

[27] M. Newville, EXAFS analysis using FEFF and FEFFIT, Journal of Synchrotron Radiation 8 (2) (2001) 96-100.

[28] C. H. Booth, F. Bridges, Improved self-absorption correction for fluorescence measurements of extended x-ray absorption fine-structure, Physica Scripta T115 (2005) 202-204.

[29] R. W. G. Wyckoff, Crystal Structures Vol. 1, Interscience Publishers, New York, New York, 1963.

[30] L. Downward, C. H. Booth, W. W. Lukens, F. Bridges, A variation of the F-Test for determining statistical relevance of particular parameters in EXAFS fits, X-Ray Absorption Fine Structure-XAFS 13882 (2007) 129131.

[31] A. I. Frenkel, C. W. Hills, R. G. Nuzzo, A view from the inside: Complexity in the atomic scale ordering of supported metal nanoparticles, The Journal of Physical Chemistry B 105 (51) (2001) 12689-12703.

[32] R. E. Benfield, Mean coordination numbers and the non-metal-metal transition in clusters, J. Chem. Soc., Faraday Trans. 88 (8) (1992) 1107-1110.

[33] H. G. Fritsche, R. E. Benfield, Exact analytical formulae for mean coordination numbers in clusters, Zeitschrift für Physik D Atoms, Molecules and Clusters 26 (1993) 15-17. 
[34] S. Calvin, M. M. Miller, R. Goswami, S. F. Cheng, S. P. Mulvaney, L. J. Whitman, V. G. Harris, Determination of crystallite size in a magnetic nanocomposite using extended $\mathrm{x}$-ray absorption fine structure, Journal of Applied Physics 94 (2003) 778.

[35] M. Borowski, A. Traverse, Study of metal clusters in AlN using RBS, RNRA and EXAFS, in: AIP Conference Proceedings, Vol. 497, 1999, pp. 687-692.

[36] M. Borowski, Size determination of small Cu-clusters by EXAFS, Le Journal de Physique IV 7 (C2) (1997) 2-2.

[37] S. Calvin, C. J. Riedel, E. E. Carpenter, S. A. Morrison, R. M. Stroud, V. G. Harris, Estimating crystallite size in polydispersed samples using EXAFS, Physica Scripta T115 (2005) 744-748.

[38] R. C. Howell, T. Proffen, S. D. Conradson, Pair distribution function and structure factor of spherical particles, Physical Review B 73 (9) (2006) 094107.

[39] M. Wojdyr, Y. Mo, E. Grzanka, S. Stelmakh, S. Gierlotka, T. Proffen, T. W. Zerda, B. Palosz, I. Szlufarska, Transition of nc-SiC powder surface into grain boundaries during sintering by molecular dynamics simulation and neutron powder diffraction, Zeitschrift für Kristallographie Supplements 26 (2007) 255-260.

[40] K. O. Hara, E. Yamasue, H. Okumura, K. N. Ishihara, Molecular dynamics study of the milling-induced allotropic transformation in cobalt, Philosophical Magazine 92 (16) (2012) 2117-2129.

[41] M. Wojdyr, debyer, http://code.google.com/p/debyer, September 4th (2012).

[42] M. Wojdyr, gosam, http://code.google.com/p/gosam/, September 4th (2012). 
[43] T. Egami, S. J. L. Billinge, Underneath the Bragg peaks: Structural Analysis of Complex Materials, Pergamon Pr, 2003.

[44] S. Calvin, S. X. Luo, C. Caragianis-Broadbridge, J. K. McGuinness, E. Anderson, A. Lehman, K. H. Wee, S. A. Morrison, L. K. Kurihara, Comparison of extended x-ray absorption fine structure and scherrer analysis of x-ray diffraction as methods for determining mean sizes of polydisperse nanoparticles, Applied Physics Letters 87 (23) (2005) 233102-233102.

[45] A. I. Frenkel, Solving the structure of nanoparticles by multiple-scattering exafs analysis, Journal of Synchrotron Radiation 6 (3) (1999) 293-295.

[46] M. Li, D. Olive, Y. Trenikhina, H. Ganegoda, J. Terry, S. A. Maloy, Study of irradiated mod. 9cr-1mo steel by synchrotron extended x-ray absorption fine structure, Journal of Nuclear Materials 441 (2013) 674-680. doi:10.1016/j.jnucmat.2012.09.039.

[47] Matzke, Hj., Radiation damage in crystalline insulators, oxides and ceramic nuclear fuels, Radiation effects 64 (1-4) (1982) 3-33.

[48] L. Van Brutzel, J. P. Crocombette, Classical molecular dynamics study of primary damage created by collision cascade in a $\mathrm{ZrC}$ matrix, Nuclear Instruments and Methods in Physics Research Section B: Beam Interactions with Materials and Atoms 255 (1) (2007) 141-145.

[49] Proffen, Th., R. B. Neder, Discus: a program for diffuse scattering and defect-structure simulation, Journal of applied crystallography 30 (2) (1997) 171-175.

[50] M. Newville, Larch: An analysis package for XAFS and related spectroscopies, in: Journal of Physics: Conference Series, Vol. 430, IOP Publishing, 2013, p. 012007.

[51] G. W. Keilholtz, R. E. Moore, M. F. Osborne, Fast-neutron effects on the carbides of titanium, zirconium, tantalum, niobium, and tungsten, Nuclear Technology 4 (5) (1968) 330-336. 


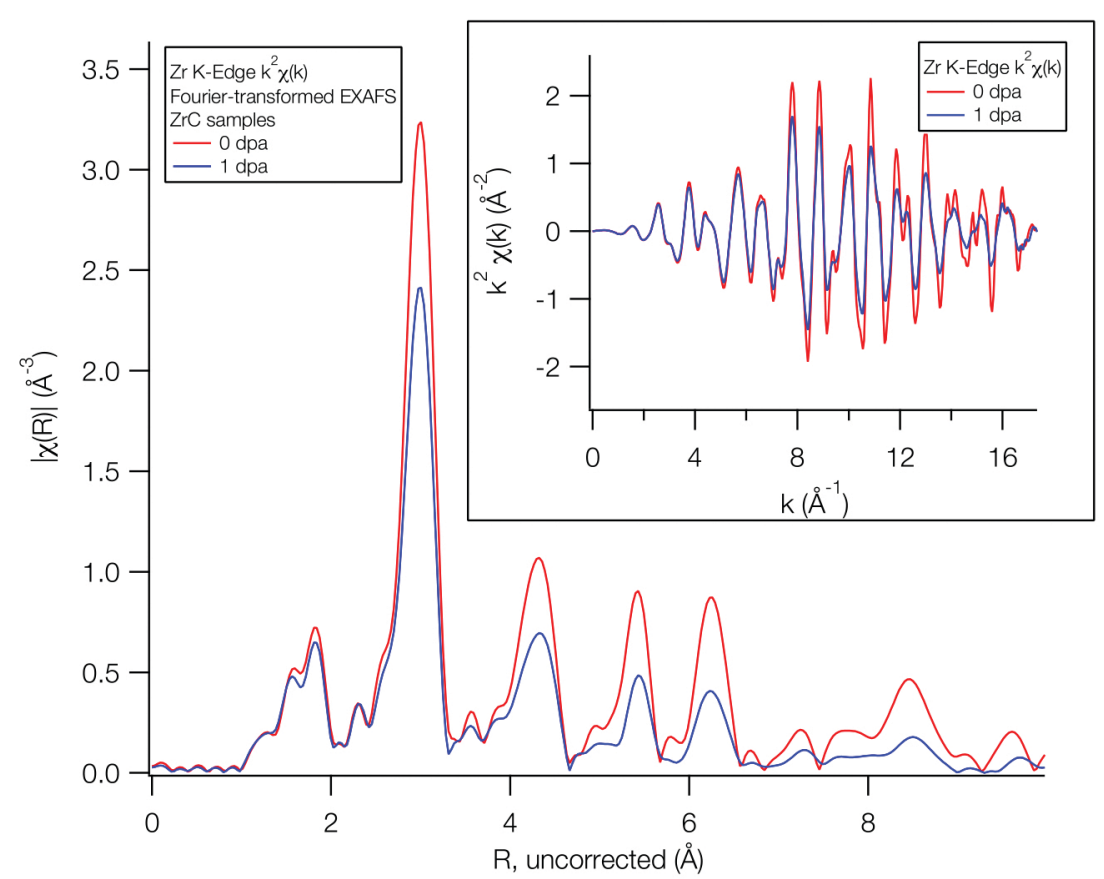

